\title{
Hyperosmolar Triggering of Histamine Release from Human Basophils
}

\author{
Steven R. Findlay, Ann M. Dvorak, Anne Kagey-SobotKa, and \\ LAWRENCE M. LICHTENSTEIN, Johns Hopkins University School of Medicine, \\ Department of Medicine, Division of Clinical Immunology, Baltimore, Maryland \\ 21239; Harvard School of Medicine, Departments of Pathology, Beth Israel \\ Hospital and Harvard Medical School, Boston, Massachusetts 02114
}

A B S T R A C T Idiopathic reactions occurring during the infusion of hyperosmolar solutions, such as radiocontrast dyes, cause a significant number of deaths each year. These reactions are similar to those which follow mediator release during allergen-induced anaphylaxis. In attempting to explain these nonimmunologic reactions, we examined the direct effect of hyperosmolarity on normal human basophils with emphasis on release induced by mannitol.

The cells of all donors released histamine in vitro in response to hyperosmolar $(0.2-0.7 \mathrm{M})$ solutions of a number of solutes including mannitol. That this was not a toxic process was supported by a number of criteria, including inhibition of release by excess stimulus at $37^{\circ} \mathrm{C}$ and a lack of release at $4^{\circ} \mathrm{C}$. Furthermore, electron microscopic studies revealed that hyperosmolar stimulation did not disrupt the cell membrane or lead to any signs of cytotoxicity. In contrast to antigen-stimulated release, where granules fuse only with the cell membrane, granules in mannitol-stimulated cells, in addition to fusing with the cell membrane, may also be extruded into a common intracellular sac before exteriorization.

Characteristics similar to antigen-induced histamine release included the time-course for release, inhibition by drugs that modify phospholipid metabolism, $p$-bromophenacyl bromide, and eicosa-5,8,11,14tetraynoic acid, and augmentation of release by deuterium oxide $\left(D_{2} O\right)$. The release process differed from antigen-induced release by a number of criteria, including independence from immunoglobulin (Ig)Erelated mechanisms, insensitivity to agonists that ele-

This is publication No. 426, O'Neill Research Laboratories, The Good Samaritan Hospital, Baltimore, Md. 21239.

Address reprint requests to Lawrence M. Lichtenstein, The Good Samaritan Hospital.

Received for publication 21 March 1980 and in revised form 26 January 1981. vate intracellular cyclic AMP, minimal dependence on extracellular calcium, lack of inhibition by 2-deoxyglucose and theophylline, and a temperature optimum of $32^{\circ} \mathrm{C}$.

We conclude that this noncytotoxic hyperosmolar release process is different from IgE-mediated secretory events and may well play a role in the idiopathic reactions which occur secondary to the infusion of hyperosmolar solutions in man.

\section{INTRODUCTION}

The etiologic role of basophil and mast cell mediators such as histamine in immunoglobulin (Ig)E-mediated anaphylactic reactions is now widely recognized (1). A similar type of "anaphylactoid" or idiopathic reaction is associated with the infusion of hyperosmolar solutions pre-operatively or during radiographic procedures. Patients often receive $30-50 \mathrm{~cm}^{3}$ of contrast media or mannitol at concentrations $>1 \mathrm{M}$. Although the idiopathic reactions described in the literature do not appear to be due to IgE-related mechanisms, the signs and symptoms of these syndromes mimic precisely the reactions which are secondary to the antigenic release of mediators $(2,3)$. In attempting to explain these nonimmunologic reactions, both direct and indirect mechanisms for the release of basophil and/or mast cell mediators have been invoked $(4,5)$.

We have examined the direct effects of hyperosmolarity on normal human basophils. It was found that mannitol and similar solutes release histamine in vitro from the cells of all donors at concentrations $>0.1$ $M$. This release mechanism is not cytotoxic, but appears to be different from any described heretofore.

\section{METHODS}

Subjects. Blood donors were all healthy volunteers between the ages of 21 and $50 \mathrm{yr}$. None of the donors had displayed idiopathic or allergic reactions to drugs. 
Reagents. The goat anti-human IgE Fc (anti-IgE) was a gift from Dr. Kimishige Ishizaka, Baltimore, Md., and eicosa-5,8,11,14-tetraynoic acid (ETYA) ${ }^{1}$ was the gift of Dr. W. E. Scott, Hoffman-LaRoche, Inc., Nutley, N. J. The following were purchased: piperazine- $N, N^{\prime} b i$ is (2-ethane-sulfonic acid) (Pipes free acid), deuterium oxide $\left(\mathrm{D}_{2} \mathrm{O}\right)$, theophylline, 2-deoxy-D-glucose, D-mannitol, $p$-bromophenacyl bromide (BPB), lactate dehydrogenase (LDH) assay kits (Sigma Chemical Co., St. Louis, Mo.); EDTA (Fisher Scientific Co., Pittsburgh, Pa.); perchloric acid $60 \%$ (J. T. Baker Chemical Co., Phillipsburg, N. J.); dextran 70 (Cutter Laboratories, Berkeley, Calif.); Hypaque 50 (Winthrop Laboratories, New York). Pipes buffer used in these experiments consisted of $\mathrm{NaCl} 110 \mathrm{mM}$, KCl $5 \mathrm{mM}$, Pipes $25 \mathrm{mM}$ (pH 7.4, adjusted using sodium hydroxide). PCM consisted of Pipes buffer plus $0.6 \mathrm{mM} \mathrm{CaCl}$ and $1 \mathrm{mM} \mathrm{MgCl}{ }_{2} . \mathrm{D}_{2} \mathrm{O}$-containing buffer stock solutions were composed of $88 \% \mathrm{D}_{2} \mathrm{O}$ and $12 \% \mathrm{H}_{2} \mathrm{O}$, vol/vol.

Histamine release and assay. Blood was drawn from normal donors and mixed to a final concentration of $0.01 \mathrm{M}$ EDTA and $20 \% \mathrm{vol} / \mathrm{vol}$ dextran 70 . Erythrocytes were allowed to sediment for $90 \mathrm{~min}$ at room temperature, and the leukocyte-rich plasma was removed. The cells were separated from the plasma by centrifugation at $180 \mathrm{~g}$ at $4^{\circ} \mathrm{C}$ for $10 \mathrm{~min}$ and were washed twice in Pipes buffer. The cells were then resuspended in $\mathrm{PCM}$ and brought to a $37^{\circ} \mathrm{C}$ reaction temperature unless otherwise specified. $0.5 \mathrm{ml}$ of the leukocyte suspension was added to $75 \times 10-\mathrm{mm}$ Falcon tubes (Falcon Labware, Div. Becton, Dickinson \& Co., Oxnard, Calif.) which contained prewarmed test solutions. After an incubation of 45 min at $37^{\circ} \mathrm{C}$ (unless otherwise specified), the cells were separated from the reaction mixture by centrifugation. The supernates were assayed for histamine using the automated fluorometric technique of Siraganian (6). The total quantity of intracellular histamine was determined from cell aliquots lysed with $2 \%$ perchloric acid. The amount of histamine released was normalized by calculation of net percent histamine released. Unstimulated cells released no more than $2 \%$ histamine. The leukocytes in $1 \mathrm{ml}$ of reaction volume equaled the number of cells obtained from $0.5 \mathrm{ml}$ of whole blood. Purified basophils were prepared as previously described (7). BPB and ETYA were solubilized in acetone and dimethyl sulfoxide, respectively, and controls for solvent effects were included in all experiments. None of the reagents used, including mannitol, fluoresced, nor did they interfere with the fluorometric assay for histamine. Hemolysis was not observed at any concentration of mannitol (or other solutes) tested.

Electron microscopy. For morphologic studies a 10-fold excess of dilute Karnovsky's fixative (8) was added directly to cell suspensions, thus halting the degranulation process instantaneously. Cells were fixed at room temperature for $1 \mathrm{~h}$ and then washed in $0.1 \mathrm{M}$ sodium cacodylate buffer, $4^{\circ} \mathrm{C}, \mathrm{pH}$ 7.4. The cells were then suspended in $1 \mathrm{~cm}^{3}$ of Hanks' balanced salt solution containing $50 \mu$ l of cationized ferritin (Miles Laboratories, Inc., Ames Div., Elkhart, Ind.) (9) and placed on a rotary shaker set at low speed for $30 \mathrm{~min}$ at room temperature. They were then washed again in $0.1 \mathrm{M}$ sodium cacodylate buffer, transferred to microtubes, and centrifuged at $1,500 \mathrm{~g}$ for $1 \mathrm{~min}$. Cell pellets were suspended in warm $2 \%$ agar and recentrifuged. The agar cell pellet was then post-fixed for $2 \mathrm{~h}$ at $4^{\circ} \mathrm{C}$ in $2 \%$ aqueous osmium tetroxide and $1.5 \%$ potassium ferrocyanide in $0.1 \mathrm{M}$ sodium phos-

${ }^{1}$ Abbreviations used in this paper: $\mathrm{BPB}, p$-bromophenacyl bromide; ETYA, eicosa-5,8,11,14-tetraynoic acid; ID $_{50}$, inhibitory dose, 50\%; LDH, lactate dehydrogenase; PCM, Pipes buffer plus $0.6 \mathrm{mM} \mathrm{CaCl}_{2}$ and $1 \mathrm{mM} \mathrm{MgCl}$; Pipes free acid, piperazine- $N, N^{\prime}$ bis (2-ethane-sulfonic acid); SRS, slowreacting substance. phate buffer, pH 6.0 (OPF method) (10). Thereafter, cell pellets were dehydrated in a graded series of alcohols and embedded in a propylene oxide-Epon sequence. Sections were cut with diamond knives, placed on copper grids, and stained with lead citrate. A single time-interval $(60 \mathrm{~min})$ following exposure to $0.75 \mathrm{M}$ mannitol (without $\mathrm{D}_{2} \mathrm{O}$ ) at $37^{\circ} \mathrm{C}$ and appropriate buffer-treated controls were studied by electron microscopy.

The question of cytotoxicity induced by mannitol was studied primarily by electron micrography. LDH studies were done on two occasions, first with basophils purified $(58 \%)$ from a patient with chronic myelogenous leukemia; the basophils had normal amounts of histamine and responded well to anti-IgE. The second experiment was with normal basophils purified by the technique of MacGlashan and Lichtenstein (7) to the point of $50 \%$ purity. In each case, the cells were exposed to $0.75 \mathrm{M}$ mannitol for $45 \mathrm{~min}$. In the first instance, there was $16 \pm 1.6 \%$ histamine release by mannitol. The net release of $\mathrm{LDH}$ was $2.7 \pm 2.5 \%$. On the second occasion, there was $46.3 \pm 3 \%$ histamine release. Net LDH release of the mannitol-challenged cells was $6.9 \pm 1.2 \%$, with a control value of $7.4 \pm 0.9 \%$.

\section{RESULTS}

Basophil histamine release in the presence and absence of $\mathrm{D}_{2} \mathrm{O}$. The dose-response relationship between the molar concentration of mannitol and the percent histamine release in the presence and absence of $44 \% \mathrm{D}_{2} \mathrm{O}$ are represented in Fig. 1. The maximal histamine release occurred at $0.75 \mathrm{M}$ mannitol $(50 \pm 5 \%$, mean $\pm S E$ ) in the presence of $\mathrm{D}_{2} \mathrm{O}$; at higher concentra-

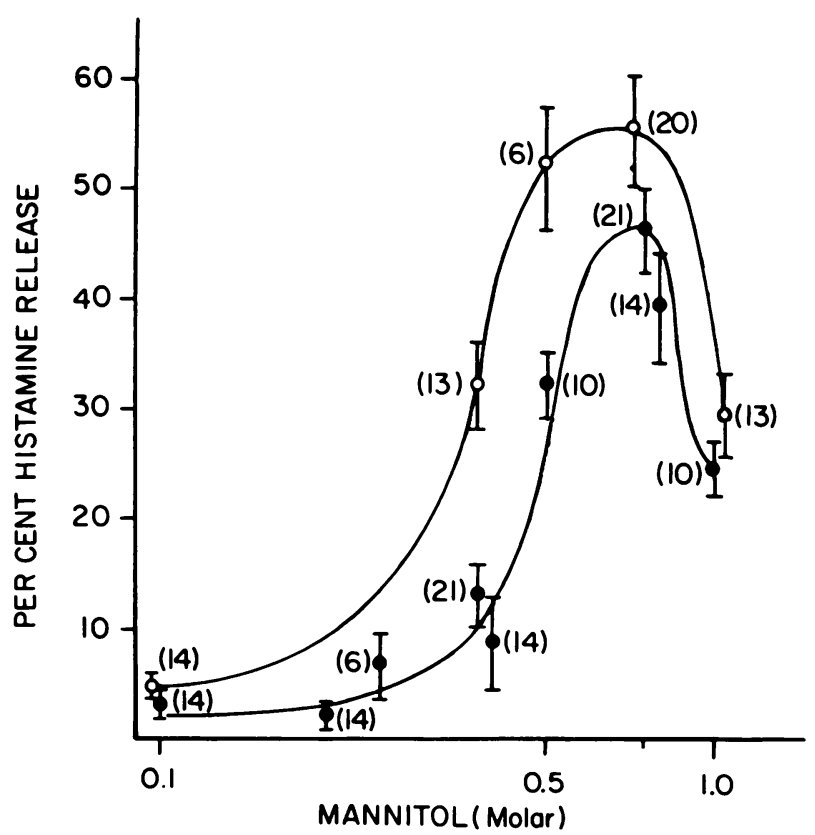

Figure 1 The percent histamine release from human basophils in vitro at various concentrations of mannitol. The results were obtained using both PCM (closed circles) or $44 \%$ $\mathrm{D}_{2} \mathrm{O}$ PCM (open circles). Numbers accompanying each point represent the number of separate experiments used in the calculation of the mean and standard error values. 
tions there was a progressive decrease in histamine release. A concentration of $0.375 \mathrm{M}$ mannitol induced little release $(13 \pm 6 \%)$, but the response was augmented considerably $(32 \pm 6 \%)$ if $44 \% \mathrm{D}_{2} \mathrm{O}$ was present. It has been shown previously that concentrations of antigen that barely reach a threshold for histamine release are greatly potentiated if $\mathrm{D}_{2} \mathrm{O}$ is substituted for $\mathrm{H}_{2} \mathrm{O}$ in the buffer solutions (11). Mannitol- and antigen-induced release are therefore analogous in that both processes are augmented by $\mathrm{D}_{2} \mathrm{O}$, although mannitol release appears to be increased somewhat less than antigen release.

It should be noted that in the routine preparations, basophils represent $<1 \%$ of the leukocyte population. In an experiment using partially purified basophils (37\% basophils, 63\% mononuclear cells) histamine release after 45 min reached $36 \%$ using $0.375 \mathrm{M}$ mannitol. Thus, following a 100-fold purification of basophils, removal of eosinophils and polymorphonuclear leukocytes, and with a ratio of mononuclear cells of basophils of 2:1 rather than the usual 100:1, the response induced by mannitol was not affected (data not shown).

To see the effects of normal human serum, dose-response curves using $0.1,0.375,0.75$, and $1 \mathrm{M}$ mannitol were carried out without serum and in the presence of 5,15 , and $25 \%$ serum. The dose-response curves were essentially identical, with slightly more release being noted in the presence of serum in one experiment and slightly less release observed in the other (data not shown).

Electron microscopy of basophils exposed to hyperosmolarity. Normal human leukocytes were exposed to $0.75 \mathrm{M}$ mannitol or buffer at $37^{\circ} \mathrm{C}$ for $60 \mathrm{~min}$ in the absence of $\mathrm{D}_{2} \mathrm{O}$, and the basophils were studied ultrastructurally. Net histamine release was $53 \%$. The majority of the basophils present in each preparation were partially granulated (type II cells [12]). These cells were characterized by a mixture of cytoplasmic granules filled with particulate material and membranebound vacuoles which were empty or contained a

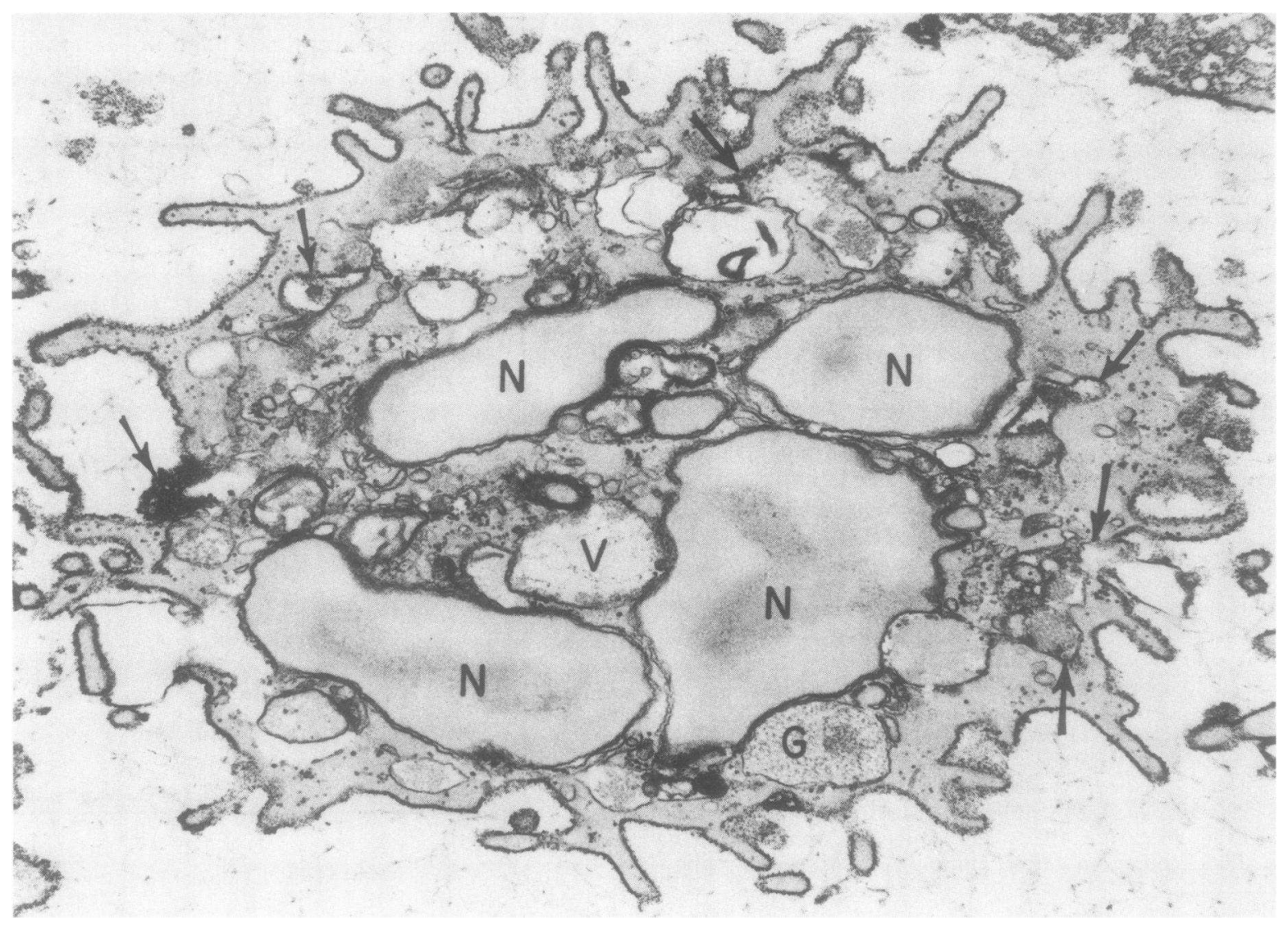

FIGURE 2 After a 60 -min exposure to $0.75 \mathrm{M}$ mannitol (53\% histamine release), this electron micrograph of a basophil (type II, see text) shows individual extrusion of membrane-free granules into cationized, ferritin-filled spaces, which are in continuity with the cell surface (arrows). Some particle-filled cytoplasmic granules $(G)$ and empty granule-vacuoles (V) remain. $N$, nucleus. $\times 22,000$. 
variable amount of granule material (Fig. 2). Mannitol caused no cytotoxic ultrastructural changes in basophils (Fig. 2), i.e., the cell membrane was intact, and the cytoplasm did not contain the extracellular marker ferritin. Cells exposed to mannitol showed exocytosis of individual granules (Figs. 2, 3A, and 4A). Extruded granules retained their particulate nature, were covered with the cationized ferritin tracer, and remained adherent to the surface of the cell (Figs. 3A and 4A). Many cytoplasmic granule-vacuoles also displayed ferritin-labeled membranes, some of which were being extruded (Fig. 3B). In some cases basophils had extruded their membrane-free granules into a centrally located, separate, membrane-bound sac (Fig. 4B). These large cytoplasmic spaces were not yet in continuity with the exterior, since these structures were not labeled with ferritin. The subplasma membrane cytoplasm of most basophils was generally devoid of granules (Fig. 4C) (except those in the active extrusion process) and was filled with a fine filamentous meshwork.

Kinetics of histamine release induced by hyperosmolar mannitol. Antigen-induced histamine release is complete (depending on the degree of antigenic stimulation) in 30-45 min (13). The time-course for mannitol-induced histamine release also varied inversely with the stimulus concentration and ranged between 45 and 60 min. Fig. 5 demonstrates the timedependent release of histamine at two different concentrations of mannitol with and without $\mathrm{D}_{2} \mathrm{O} . \mathrm{D}_{2} \mathrm{O}$ accel- erated the release process, especially at early times, when $0.75 \mathrm{M}$ mannitol was used. Histamine release at the lower concentration $(0.375 \mathrm{M})$ was low and occurred very slowly in buffer alone. Both the rate and magnitude of release were markedly augmented in the presence of $\mathrm{D}_{2} \mathrm{O}$. All subsequent reactions were performed using the 45-min incubation period.

Temperature dependence of histamine release by hyperosmolar mannitol. As previously reported (13), the optimum temperature for histamine release induced by anti-IgE or antigen was $37^{\circ} \mathrm{C}$ (Fig. 6A). In contrast, the optimum temperature for mannitol-induced histamine release at several concentrations was $32^{\circ} \mathrm{C}$ (Fig. $\left.6 \mathrm{~B}-\mathrm{D}\right)$. At $4^{\circ} \mathrm{C}$, release did not occur with any concentration of mannitol tested.

Desensitization with anti-IgE and its effect on the hyperosmolar release of histamine by mannitol. In three separate experiments, one of which is shown in Fig. 7, normal leukocytes were nonspecifically desensitized with a high concentration of anti-IgE in the absence of calcium. This procedure is nonspecific because it deactivates all IgE-dependent release mechanisms (14). In each experiment, rechallenge of the leukocytes revealed that anti-IgE no longer caused histamine release (Fig. 7, upper left, insert). When these desensitized cells were challenged with hyperosmolar concentrations of mannitol, however, the cells were quite responsive. In fact, the desensitized cells were consistently slightly more reactive than non-desensitized cells (arrows, Fig. 7). This was true whether
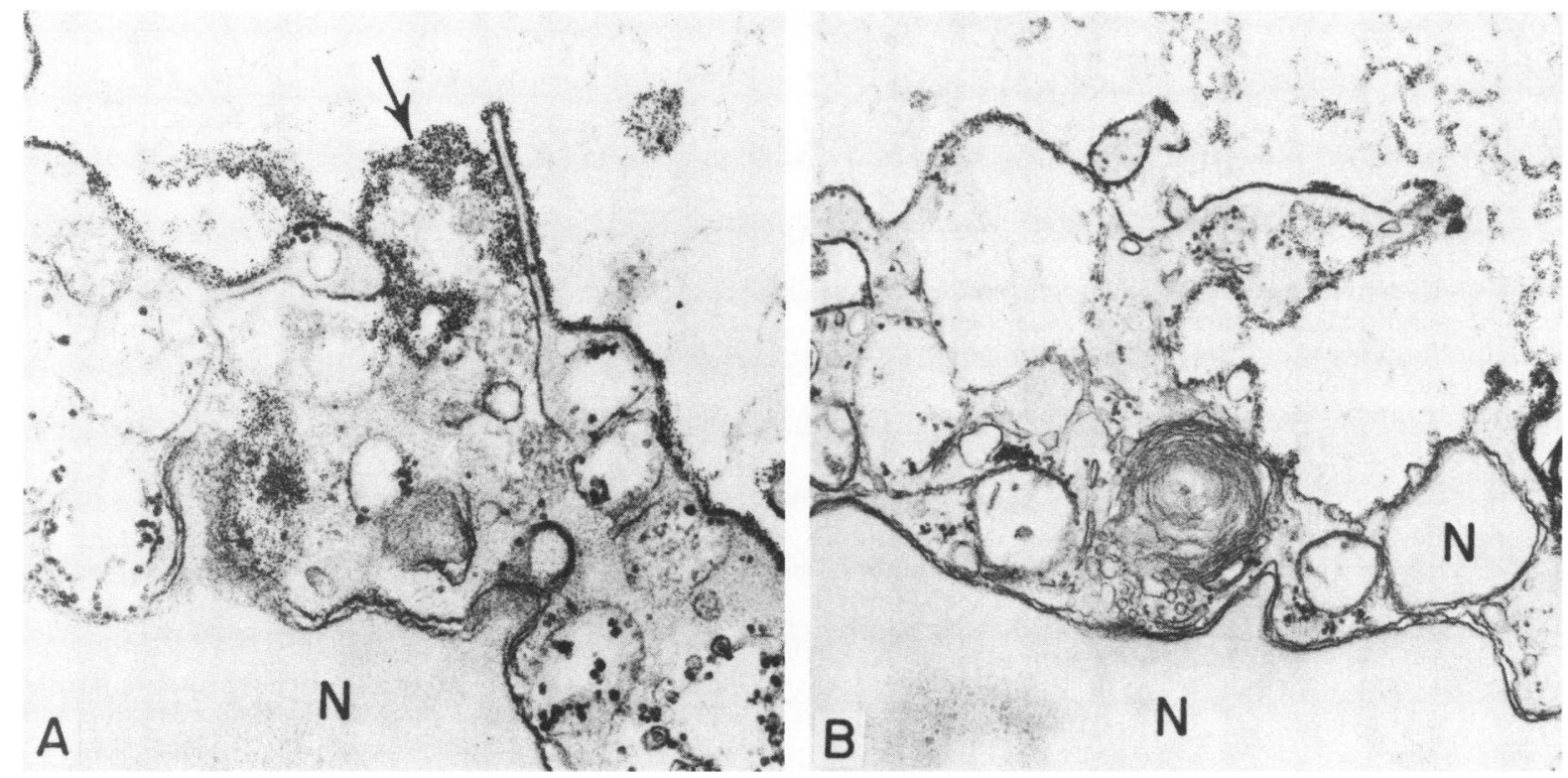

FIGURE 3 Electron microphotographs of two basophils prepared as in Fig. 2. In Fig. 3A, cationized ferritin covers the extruded membrane-free granule on the cell surface (arrow), as well as the surface of the basophil. In Fig. 3B, large empty granule-vacuole spaces are lined by the tracer and are being extruded. $N$, nucleus. $A, \times 42,000 ; B, \times 26,000$. 

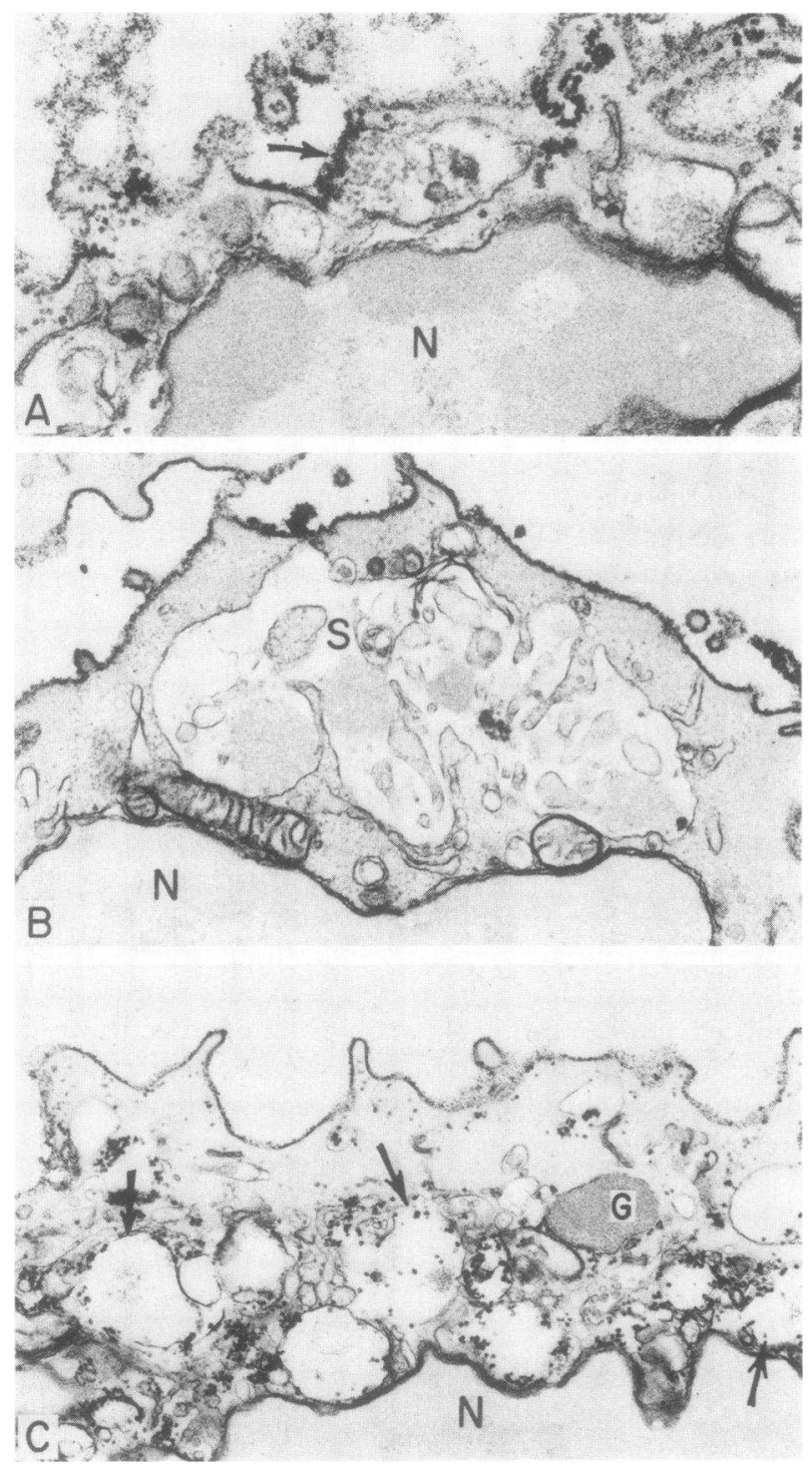

FIgURE 4 Electron micrographs of basophils after exposure to $0.75 \mathrm{M}$ mannitol for $60 \mathrm{~min}$. In Fig. $4 \mathrm{~A}$, a membrane-free granule in the process of extrusion is in continuity with the cell surface and is labeled with cationic ferritin (arrow). In Fig. 4B, a centrally located, membrane-bound cytoplasmic sac(s) contains membrane-free granules. Cationized ferritin labels the cell surface, but has not entered this space, indicating that it is not yet open to the exterior of the cell. In $4 \mathrm{C}$ the subplasma membrane cytoplasmic area is devoid of granules. Deeper within the cell, an unaltered granule (G) and several partially filled granule-vacuoles are seen (arrows). No ferritin is present in these. They are therefore not yet open to the exterior. $\mathrm{N}$, nucleus. $\mathrm{A}, \times 42,000 ; \mathrm{B}, \times 21,000 ; \mathrm{C}$, $\times 22,000$.

the cells were challenged with mannitol in the presence or absence of $\mathrm{D}_{2} \mathrm{O}$.

Modulation of hyperosmolar, mannitol-induced histamine release. In contrasting the hyperosmolar
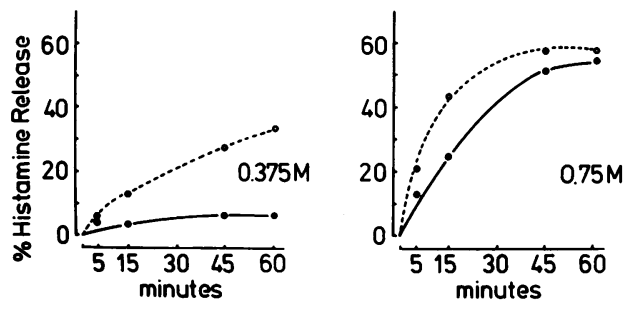

Figure 5 The time-dependent release of histamine from normal leukocytes at two concentrations of mannitol in a single experiment, using PCM (closed circles) or $44 \% \mathrm{D}_{2} \mathrm{O}$ PCM (open circles). Similar results were obtained in three separate experiments using leukocytes from different donors.

dependent release process with anti-IgE-induced release, we characterized each process using $(a)$ the divalent cation chelator EDTA; $(b)$ heat pretreatment of cells; $(c)$ the metabolic inhibitor 2-deoxyglucose; and (d) the cyclic AMP-active drug theophylline (Table I). As shown, anti-IgE-induced release is almost completely inhibited under each condition. Unlike the anti-IgE-dependent process, either pretreatment of cells with heat $\left(30 \mathrm{~min}\right.$ at $\left.47^{\circ} \mathrm{C}\right)$ or the addition of EDTA $(1 \mathrm{mM})$ only partially reduced the histamine release response to 1.0 and $0.75 \mathrm{M}$ mannitol. At the lowest

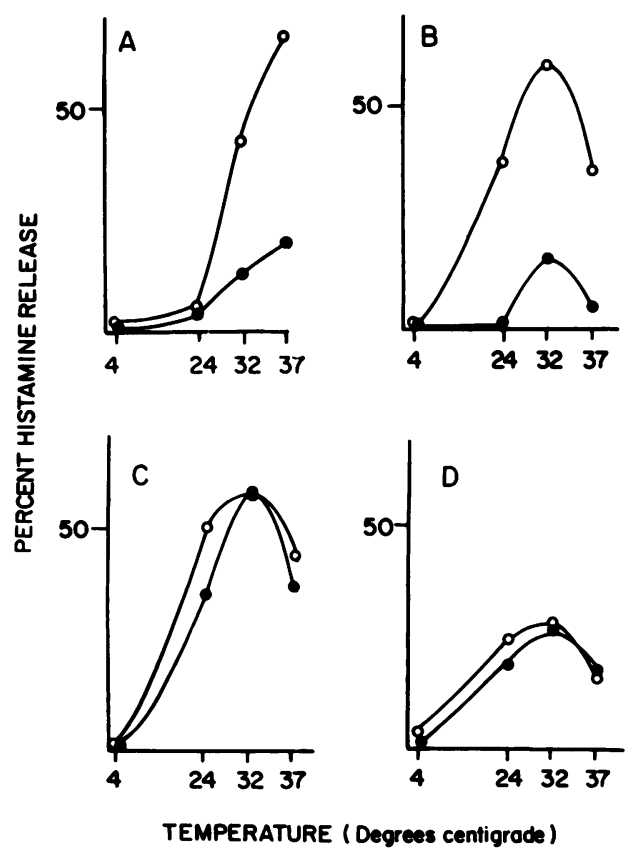

FigURE 6 The temperature dependence of histamine release elicited by anti-IgE or hyperosmolar mannitol using normal leukocytes. Similar results were obtained in three separate experiments, one of which is depicted. Panel A depicts the percent release obtained using $0.1 \mu \mathrm{g} / \mathrm{ml}$ anti-IgE. Panels B, C, and $D$ depict percent release obtained using $0.375,0.75$, and $1 \mathrm{M}$ mannitol, respectively, in the absence (closed circles) and presence (open circles) of $\mathrm{D}_{2} \mathrm{O}$. 


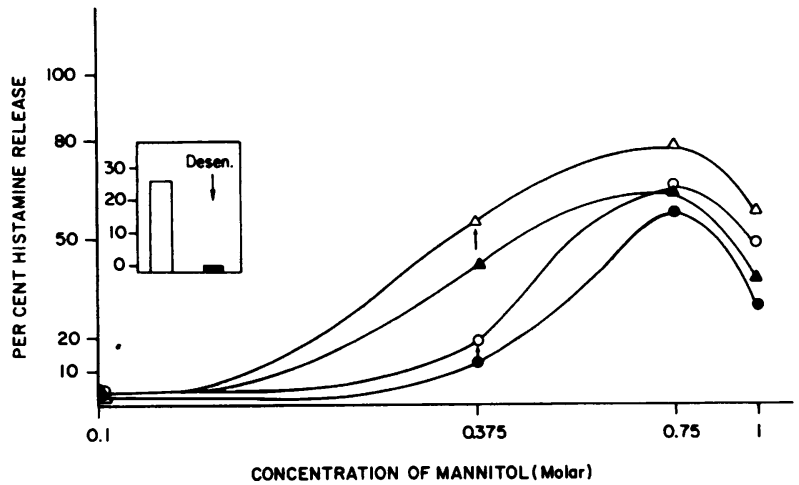

Figure 7 The percent histamine release in response to mannitol in normal non-desensitized and anti-IgE-desensitized leukocytes is shown. The insert shows that normal, nondesensitized cells, released $26 \%$ histamine (open bar). After desensitization, the leukocytes did not release histamine (closed bar). Desensitizing conditions were anti-IgE $1 \mu \mathrm{g} / \mathrm{ml}$, EDTA $1 \mathrm{mM}$, at $37^{\circ} \mathrm{C}$ for $30 \mathrm{~min}$ in Pipes buffer. Non-desensitized cells were incubated similarly but without anti-IgE. Cells were washed twice in Pipes buffer prior to challenge with $0.1 \mu \mathrm{g} / \mathrm{ml}$ anti-IgE or mannitol. When suspended in PCM (circles) or in $44 \% \mathrm{D}_{2} \mathrm{O}$ PCM (triangles), desensitized cells (open symbols) released more histamine (arrows) than nondesensitized cells (closed symbols)

concentration of mannitol tested $(0.375 \mathrm{M})$, treatment with EDTA and heat markedly reduced histamine release; theophylline had no effect, and 2-deoxyglucose enhanced release. Thus, 2 -deoxyglucose $\left(10^{-3} 1 \mathrm{mM}\right)$ and theophylline ( $1 \mathrm{mM}$ ) had no inhibitory effect on mannitol-induced histamine release at any concentration tested. Also, in three successive experiments, changing the external calcium concentration (0-1 mM) did not influence mannitol-induced release (data not shown). The data contained in Table I suggest that more than one release mechanism is triggered by hyperosmolarity. For example, with high concentrations of mannitol $(1.0 \mathrm{M})$, release is statistically unal- tered by the presence of EDTA, heat, or 2-deoxyglucose. On the other hand, inhibition by EDTA and heat exceeds $50 \%$ at the low concentration $(0.375 \mathrm{M})$. This suggestion is strengthened by the observation that, at high concentrations of mannitol, 2-deoxyglucose had little effect, whereas at the lower concentration, there was a consistent augmentation, seen in three of three experiments.

The effects of inhibitors of phospholipid metabolism on hyperosmolar histamine release. Although the inhibitors and conditions cited above had little or no effect on the hyperosmolar release reaction, the effects of drugs which purportedly act on phospholipid metabolism were similar to those observed on IgE-mediated release. ETYA, which blocks both the cyclooxygenase and the lipoxygenase pathways of arachidonic acid metabolism $(15,16)$, inhibits anti-IgE-induced histamine release with an inhibitory dose, $50 \%\left(\mathrm{ID}_{50}\right)$, of 40 $\mu \mathrm{M}$ (Fig. 8a). A similar effect of ETYA is seen on hyperosmolar release with an $\mathrm{ID}_{50}$ at a threefold higher concentration $(120 \mu \mathrm{M})$. BPB, a phospholipase $\mathrm{A}_{2}$ inhibitor (17), blocks release by both types of stimuli at concentrations in the range of $0.4-0.8 \mathrm{M}$ (Fig. 8b).

Histamine release as a function of osmolarity. To determine whether osmolarity alone could explain the histamine release obtained in vitro, we challenged leukocytes with several different hyperosmolar solutions. Fig. 9 presents the result of one of three experiments comparing histamine release in response to hyperosmolar solutions of sodium chloride, dextrose, Hypaque 50, and mannitol. Hyperosmolar sodium chloride was much less effective than the other compounds tested in releasing histamine. In similar experiments, mannitol was compared with its isomer, sorbitol, and to other polyhydric alcohols-erythritol $\left(\mathrm{C}_{4}\right)$, xylitol $\left(\mathrm{C}_{5}\right)$, and persitol $\left(\mathrm{C}_{7}\right)$. Both in the presence of $\mathrm{D}_{2} \mathrm{O}$ and in PCM, all of these agents gave similar or identical release at equivalent molar concentrations (data not shown).

Release of mediators other than histamine. 13 ex-

TABLE I

Comparison of the Effect of EDTA, Heat, and Drugs on Histamine Release by Mannitol and Anti-IgE

\begin{tabular}{|c|c|c|c|c|c|c|c|c|}
\hline \multirow{2}{*}{$\begin{array}{l}\text { Mannitol concentration } \\
\text { in PCM }\end{array}$} & \multicolumn{2}{|c|}{ EDTA (1 mM) } & \multicolumn{2}{|c|}{ Heat $\left(47^{\circ} \mathrm{C}\right)$} & \multicolumn{2}{|c|}{ 2-Deoxyglucose (1 mM) } & \multicolumn{2}{|c|}{ Theophylline (1 mM) } \\
\hline & - & + & - & + & - & + & - & + \\
\hline$M$ & \multicolumn{8}{|c|}{$\%$ release } \\
\hline 1.0 & $22.7 \pm 3^{*}$ & $21.6 \pm 5^{*}$ & $20.5 \ddagger$ & $20.0 \$$ & $24.6 \pm 1^{*}$ & $22.0 \pm 4^{*}$ & $24.6 \pm 1^{*}$ & $27.0 \pm 1^{*}$ \\
\hline 0.75 & $52.6 \pm 8 \oint$ & $41.0 \pm 8 \S$ & $51.5 \pm 11^{\prime \prime}$ & $19.0 \pm 7^{\prime \prime}$ & $39.7 \pm 3^{*}$ & $39.8 \pm 3^{*}$ & $39.7 \pm 3^{*}$ & $41.0 \pm 2 *$ \\
\hline 0.375 & $19.6 \pm 9 \S$ & $6.8 \pm 4 \S$ & $18.0 \pm 13^{\prime \prime}$ & $9.0 \pm 2^{\prime \prime}$ & $9.7 \pm 5^{*}$ & $30.0 \pm 4^{*}$ & $9.7 \pm 5^{*}$ & $8.7 \pm 7 *$ \\
\hline Anti-IgE $(0.1 \mu \mathrm{g} / \mathrm{ml})$ & $57.6 \pm 10 \S$ & $1.8 \pm 1 \S$ & $53.0 \pm 12^{\prime \prime}$ & $2.5 \pm 1^{11}$ & $51.6 \pm 4^{*}$ & $7.6 \pm 4^{*}$ & $51.6 \pm 4^{*}$ & $9.3 \pm 6^{*}$ \\
\hline
\end{tabular}

Values are the mean alone or mean $\pm \mathrm{SE}$.

$* n=3$.

$\ddagger n=2$.

$\S n=5$.

$\| n=4$. 

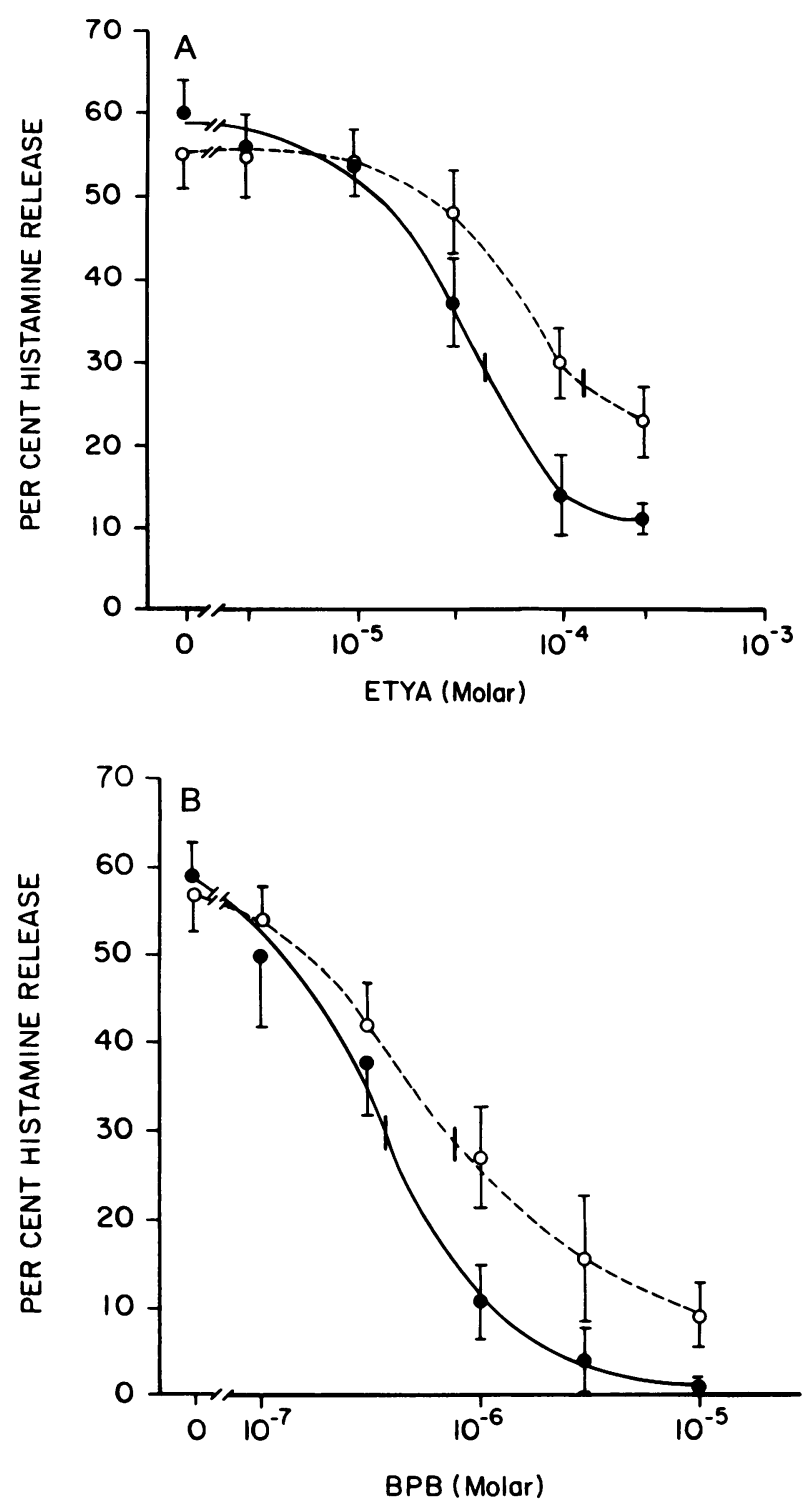

Figure 8 (A) The release of histamine in the absence or presence of ETYA $\left(3 \times 10^{-6}\right.$ to $\left.3 \times 10^{-4} \mathrm{M}\right)$. In four separate experiments, mannitol $(0.75 \mathrm{M})$ or anti-IgE $(0.1 \mu \mathrm{g} / \mathrm{ml})$ was used to challenge leukocytes which had been pretreated with drug for $10 \mathrm{~min}$. The $\mathrm{ID}_{50}$ was about $120 \mu \mathrm{M}$ for mannitol (open circles) and $40 \mu \mathrm{M}$ for anti-IgE (solid circles). With both stimuli incubations proceeded at $37^{\circ} \mathrm{C}$ for $45 \mathrm{~min}$. Brackets represent the standard error of the mean values. The vertical bars on each log dose-response curve mark $50 \%$ inhibition of release. (B) The release of histamine in the presence of BPB $\left(10^{-7}-10^{-5} \mathrm{M}\right)$. Concentrations of stimuli, incubation time, temperature, and symbols are the same as in Fig. 8A. The ID $_{50}$ for mannitol was $0.78 \mu \mathrm{M}$, and for anti-IgE, $0.37 \mu \mathrm{M}$. Standard error brackets enclose mean values from four experiments.

periments were carried out to ascertain whether mannitol released slow reacting substance (SRS) (18). The leukocytes were used at concentrations ranging from

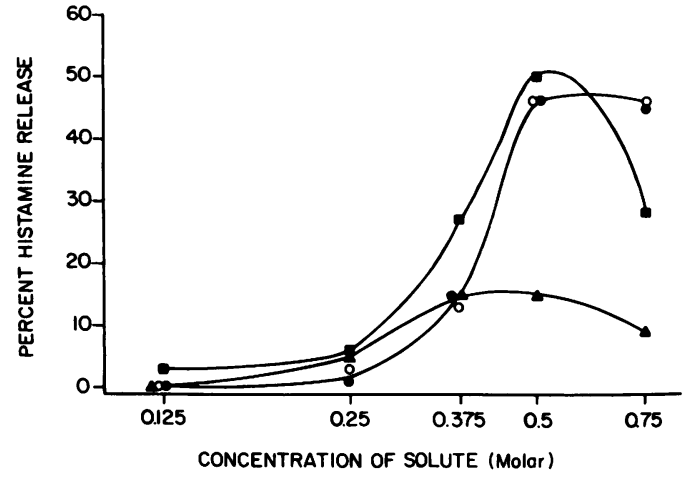

Figure 9 The net percent histamine release in response to hyperosmolar solutions. Sodium chloride ( $\Delta$ ), Hypaque 50 $(\square)$, dextrose ( $)$, and mannitol $(O)$ were incubated with leukocytes at $37^{\circ} \mathrm{C}$ for $45 \mathrm{~min}$. Two other experiments gave similar patterns of release.

$5 \times 10^{7}$ to $10^{8} / \mathrm{ml}$, and the concentration of mannitol was $0.75 \mathrm{M}$. The histamine release averaged $44 \pm 30.7 \%$, with a range from 9 to $95 \%$. SRS was undetectable in any of these specimens; the limit of SRS detection was $70 \mathrm{U} / \mathrm{ml}$. With similar amounts of histamine release induced by antigen or anti-IgE, there would have been detectable SRS (18). Three experiments were carried out to see whether another preformed mediator, $p$ toluene sulfonyl-L-arginine (TAMe) esterase, was released $(19,20)$. In each case, the dose-response curves for histamine and esterase release were similar in shape, although, as previously reported, there was no quantitative relationship between the two (data not shown). Thus, like C5a, mannitol appears to release preformed, but not newly synthesized, basophil mediators.

\section{DISCUSSION}

Idiopathic reactions to a number of substances which are infused into humans at high molar concentrations, e.g., mannitol and radiocontrast media, appear to be independent of classic anaphylactic mechanisms. We have attempted to determine the characteristics of these reactions by studying the direct effects of hyperosmolar solutions of mannitol on human basophils. In every donor tested, histamine release was obtained at concentrations between 0.3 and $1 \mathrm{M}$ mannitol. A number of polyhydric alcohols were found to substitute readily for mannitol. Hyperosmolar sodium chloride was, however, not as effective. The reasons for this are not clear, but may lie in the relative ease of transmembrane diffusion of these ions as compared with the other solutes. It is also possible that the high concentrations of these ions play an independent inhibitory role, thus preventing hyperosmolar triggering of release.

The release process in normal donors does not appear to be toxic or lytic and does not depend on basophilbound IgE. These conclusions were based on the 
following data: $(a)$ the release process was inhibited by concentrations of mannitol $>0.75 \mathrm{M}$; $(b)$ release did not occur at $4^{\circ} \mathrm{C}$ and was inhibited at temperatures of $>32^{\circ} \mathrm{C}$; $(c)$ release was partially inhibited by heat pretreatment and EDTA; $(d) 100 \%$ release was never observed $(n=21)$, nor was hemolysis noted; $(e)$ inhibitors of phospholipid and arachidonate metabolism (BPB, ETYA) very effectively inhibited release by mannitol; $(f)$ cells desensitized nonspecifically by anti-IgE released histamine in response to mannitol; ( $g$ ) LDH release from human basophils was minimal following mannitol exposure; and $(h)$ electron micrographic studies of basophils exposed to hyperosmolar mannitol $(0.75 \mathrm{M})$ showed exclusion of generalized cytoplasmic staining with the tracer ferritin. The basophils in this study also showed none of the characteristics of damaged cells, such as membrane breakage, swollen organelles, lucent cytoplasm, or nuclear pyknosis. The most conclusive evidence that the cells in these studies were not damaged is, however, that they totally excluded the extracellular tracer ferritin.

It is of considerable interest that drugs which affect glucose metabolism (2-deoxyglucose) or intracellular cyclic AMP levels do not inhibit hyperosmolar release. This is in marked contrast to IgE-mediated release. On the other hand, ETYA and BPB, which impair phospholipid and arachidonate metabolism, inhibited hyperosmolar release at concentrations similar to those effective in IgE-mediated reactions. The only precedent for this pattern of inhibition can be found in recent experiments carried out in our laboratory with phorbol myristate acetate-induced release. This release is a slow, noncytotoxic process that is variably affected by cyclic AMP-active drugs and is only partially dependent upon calcium. Phorbol myristate acetate-induced release is, however, completely inhibited by ETYA and BPB. Possibly both phorbol myristate acetate and mannitol induce release by a unique mechanism which involves the activation of phospholipid metabolism.

The experiment with partially purified basophils (37\%) suggests that cell-cell interaction plays a minor role in mannitol-induced release of basophil histamine. The basophils responded very well in the absence of polymorphonuclear leukocytes and eosinophils, and with greatly reduced numbers of mononuclear cells relative to basophils.

Previously, using similar techniques, we described the morphology of antigen-induced IgE-mediated degranulation of human basophils (12). In that study it was useful to classify basophils before antigenic stimulation, but after isolation procedures, as type I (fully granulated), type II (partially granulated), or type III (cytoplasm-containing granule-vacuoles that were completely devoid of granule particulate content). Following exposure to antigen, individual granules fused with the cell membrane at multiple points, and the granule contents were extruded, often remaining attached to the cell membrane for a short time. This process paralleled the release of histamine, and resulted in viable cells which were devoid of all granules, except for a smaller, less dense granule type which was not extruded. When histamine release was completed and high $(>90 \%)$, one could no longer find any type II cells.

Both significant differences and similarities between the antigen-stimulated process described above and the mannitol-induced degranulation were noted. Using normal donor cells, we found nearly all basophils exposed to mannitol $(0.75 \mathrm{M})$ to be type II, i.e., partially granulated. In other words, in nearly all of these cells individual granule extrusion was present, but the cells also retained numerous granules and granule-vacuoles. Cationized, ferritin-stained, empty vacuoles were numerous, indicating continuity with the cell surface. Extrusion of the membranes of previously emptied granules also was a prominent process. Granule extrusion was never seen in control cells.

Many of the remaining granules were centrally located. Often this process left the cytoplasm beneath the cell surface devoid of granules and filled with a more extensive filamentous array than was seen in control cells or in cells undergoing degranulation in response to antigen. A small number of basophils were present with centrally placed sacs filled with membrane-free granules. These sacs were not yet in continuity with the exterior, as the cationic ferritin tracer was not present in these sacs. These central granule-containing sacs induced by mannitol are similar to those found after the anaphylactic degranulation of guinea pig basophils, a process which is morphologically dissimilar to that of human basophils $(21,22)$. These morphological differences between IgE-mediated and mannitol-induced degranulation of human basophils, although subtle, clearly distinguish between these release mechanisms.

We chose to study the direct effect of mannitol and other hyperosmolar solutions on basophil histamine release in the absence of serum since we observed no differences in release with or without serum. Also, although involvement of the complement system has been implicated both in vivo and in vitro $(23,24)$ in animals (25) and in man (26), no definitive correlations have been established between the changes noted and clinical reactions. Too, controversy exists as to the pathway activated $(23,27)$ and whether the decrease in complement components is due to true activation or to nonsequential cleavage of components of this system by the contrast media or by proteases involved in the clotting cascade (28).

In summary, we have described a unique noncytotoxic mechanism for histamine release from basophils exposed to hyperosmolar solutions. When considering 
the clinical implications of this work, it should be noted that the hyperosmolar-dependent histamine release occurred using cells of all donors. We would therefore expect all patients receiving a rapid hyperosmolar infusion to release histamine. In fact, this has recently been demonstrated in patients undergoing cardiac catheterization (27). Anaphylactoid reactions in response to hyperosmolar glucose infusions have also recently been reported (29). It is likely that the mast cell, another IgE-bearing, histamine-containing cell is responsible for such reactions in vivo. Rockoff and coworkers (30) suggested that contrast media released histamine from mast cells due to their hyperosmolarity and Mann (31) in the 1960's first suggested the involvement of histamine in anaphylactoid reactions to radio-contrast media (3i). More recently, in vivo histamine release has been found in rabbits following infusion of hyperosmolar solutions (25). Additionally, our data, as well as those of Rockoff et al. (30), show that, of the solutes used, $\mathrm{NaCl}$ was the least effective in causing mediator release or changes in complement components. Whether a hyperosmolar-dependent release process is principally responsible for severe anaphylactic-like reactions has not yet been established. It has been noted, however, that there are marked differences in the "releasability" of histamine and other mediators in the cells of patients with asthma and urticaria (32). Therefore, there may exist individuals who are abnormally sensitive to hyperosmolar stimuli. We have observed one such patient whose bronchospastic reaction to mannitol infusion was associated with an increased (twofold) in vitro sensitivity of his basophils to mannitol. It was, in fact, this patient who initiated the studies described above (manuscript in preparation).

\section{ACKNOWLEDGMENTS}

We thank Kathryn Pyne for photographic assistance with the electron micrographs and Shy-Yuan Chi for expert technical assistance during these studies. We also greatly appreciate the work of Freda Glasser, who performed the histamine release experiments.

This work was supported by grants HL 14153 and HL 23586 from the National Heart, Lung and Blood Institute, National Institutes of Health, and by grant CA 19141 from the National Cancer Institute. Dr. Findlay is the recipient of Research Fellowship Award AII 07056.

\section{REFERENCES}

1. Orange, R. P., and G. J. Donsky. 1978. Anaphylaxis. In Allergy: Principles and Practice. E. Middleton, Jr., C. E. Reed, and E. F. Ellis, editors. The C. V. Mosby Company, St. Louis, Mo. Chapter 32 pp. 563-573.

2. Davids, P., M. B. Roberts, and J. Roylance. 1975. Acute reactions to urographic contrast media. Br. Med.J. 2: 434 .

3. Gorevic, P., and A. P. Kaplan. 1979. Contrast agents and anaphylactic-like reactions. J. Allergy Clin. Immunol. 63: 225-227.

4. Lasser, E. C., A. J. Walters, and J. H. Lang. 1974. An ex- perimental basis for histamine release in contrast material reactions. Radiology. 110: 49-59.

5. Arroyave, C. M., and E. M. Tan. 1977. Mechanism of complement activation by radiocontrast media. Clin. Exp. Immunol. 29: 89-94.

6. Siraganian, R. P. 1976. Histamine release and assay methods for the study of human allergy. In Manual of Clinical Immunology. N. R. Rose and H. Friedman, editors. American Society for Microbiology, Washington, D. C. 603-615.

7. MacGlashan, D. W., and L. M. Lichtenstein. 1980. The purification of human basophils. J. Immunol. 124: 2519-2521.

8. Karnovsky, M. J. 1967. The ultrastructural basis of capillary permeability studied with peroxidase as a tracer. J. Cell Biol. 35: 213.

9. Danen, D., L. Goldstein, Y. Marikovsk, and E. Skultelsky. 1972. Use of cationized ferritin as a label of negative charges on cell surfaces. J. Ultrastruc. Res. 38: 500 .

10. Dvorak, A. M., M. E. Hammond, H. F. Dvorak, and M. J. Karnovsky. 1972. Loss of cell surface material from peritoneal exudate cells associated with lymphocyte-mediated inhibition of macrophage migration from capillary tubes. J. Lab. Invest. 27: 561 .

11. Gillespie, E., and L. M. Lichtenstein. 1972. Histamine release from human leukocytes: studies with deuterium oxide, colchicine and cytochalasin B. J. Clin. Invest. 51: 2941-2947.

12. Dvorak, A. M., H. H. Newball, H. F. Dvorak, and L. M. Lichtenstein. 1980. Antigen-induced IgE-mediated degranulation of human basophils. J. Lab. Invest. 43: 126- 139.

13. Lichtenstein, L. M., and A. G. Osler. 1964. Studies on the mechanism of hypersensitivity phenomena. IX. Histamine release from human leukocytes by ragweed pollen antigen. J. Exp. Med. 120: 507-530.

14. Sobotka, A. K., M. Dembo, B. Goldstein, and L. M. Lichtenstein. 1979. Antigen-specific desensitization of human basophils. J. Immunol. 122: 511-517.

15. Flower, R. J. 1974. Drugs which inhibit prostaglandin biosynthesis. Pharmacol. Rev. 26: 33-67.

16. Bills, T. K., J. B. Smith, and M. J. Silver. 1976. Metabolism of $\left[{ }^{14} \mathrm{C}\right]$ arachidonic acid by human platelets. Biochim. Biophys. Acta. 424: 303-314.

17. Volwerk, J. J., W. A. Pieterson, and G. H. deHaas. 1974. Histidine at the active site of Phospholipase $\mathrm{A}_{2}$. Biochemistry. 13: 1446-1454.

18. Findlay, S. R., L. M. Lichtenstein, and J. A. Grant. 1980. Generation of slow reacting substance by human leukocytes. II. Comparison of stimulation by antigens, antiIgE, calcium ionophore A23187 and C5-peptide. J. Immunol. 124: 238-242.

19. Newball, H . H., R. W. Berninger, R. C. Talamo, and L. M Lichtenstein. 1979. Anaphylactic release of a basophil kallikrein-like activity. I. Purification and characterization. J. Clin. Invest. 64: 457-465.

20. Newball, H. H., R. C. Talamo, and L. M. Lichtenstein 1979. Anaphylactic release of a basophil kallikrein-like activity. II. A mediator of immediate hypersensitivity reactions. J. Clin. Invest. 64: 466-475.

21. Dvorak, A. M. 1978. Biology and morphology of basophilic leukocytes. In Immediate Hypersensitivity, Modern Concepts and Developments. M. K. Bach, editor. Marcel Dekker, Inc., New York. 7: 369-405.

22. Dvorak, A. M., and H. F. Dvorak. 1979. The basophil. Its morphology, biochemistry, motility, release reactions, recovery and role in the inflammatory response of IgE- 
mediated and cell-mediated origin. Arch. Pathol. Lab. Med. 103: 551-557.

23. Arroyave, C. M., K. N. Blat, and R. Crown. 1976. Activation of the alternative pathway of the complement system by radiocontrast media. J. Immunol. 117: 1866-1869.

24. Arroyave, C. M., M. D. Schatz, and R. A. Simon. 1979. Activation of the complement system by radiographic contrast media: studies in vivo and in vitro. J. Allergy Clin. Immunol. 63: 276-280.

25. Ring, J., B. Endrich, and M. Intaglietta. 1978. Histamine release, complement consumption and microvascular changes after radiographic contrast media infusion in rabbits. J. Lab. Clin. Med. 92: 584-594.

26. Ring, J., C. M. Arroyave, M. J. Fritzler, and E. M. Tan. 1978. In vitro histamine and serotonin release by radiographic contrast media. Complement dependent and independent release reaction and changes in ultrastructure of human blood cells. Clin. Exp. Immunol. 32: 105-118.

27. Cogen, F. C., M. E. Norman, E. Dunsky, J. Hirshfeld, and
B. Zweiman. 1979. Histamine release and complement changes following injection of contrast media in humans. J. Allergy Clin. Immunol. 64: 299-303.

28. Kolb, W. P., J. H. Lang, and E. C. Lasser. 1978. Nonimmunologic complement activation in normal human serum induced by radiographic contrast media. J. Immunol. 121: 1232-1238.

29. Czary, D., P. Prichard, S. Lewis, and M. Fennesy. 1979. $50 \%$ dextrose-induced anaphylactic syndrome. X International Congress of Allergology, Jerusalem, 4-11 November. 62

30. Rockoff, S. D., R. Brasch, C. Kuhn, and M. Chraplyvy. 1970. Contrast media as histamine liberators I. Mast cell histamine cell release in vitro by sodium salts of contrast media. Invest. Radiol. 5: 503-509.

31. Mann, M. R. 1961. The pharmacology of contrast media. Proc. R. Soc. Med. 54: 473-476.

32. Findlay, S. R., and L. M. Lichtenstein. 1980. Basophil "releasability" in patients with asthma. Am. Rev. Respir. Dis. 122: 53-59. 